\title{
Straight-washing ecological legacies
}

To the Editor - Scientists are human, and scientists are diverse. But this diversity is nothing unless people can be themselves while practising science ${ }^{1}$. This should extend to acknowledging 'hidden' diversities of the scientists that changed our understanding of the world. This is important not only for historical accuracy but also because it provides role models for today's diverse scientific communities.

The eighteenth-century scientist Alexander von Humboldt was one such scientist. He was a founder of geography and ecology; his expeditions across the world gave rise to biogeography, and he showed the "connectivity of nature" ${ }^{\text {. }} \mathrm{He}$ was one of the first physical geographers, linking exploitation of nature and damage to ecosystems. This is the 250th anniversary of his birth, and Nature Ecology \& Evolution rightly celebrated his achievements through an Editorial ${ }^{3}$ and a collection of papers that "look back over his life and compile a collection of articles inspired by his legacy". However, in highlighting aspects of Humboldt's personal life, but simultaneously excluding his well-documented infatuations with and attractions to men $^{2}$, the Editorial perpetuates a culture of 'straight-washing'. Whether this is deliberate or not, it divorces von Humboldt's real self from his science, hiding the queerness of an important scientist. We write to highlight the importance of teams of diverse people, and the need to have visible role models to increase retention of under-represented groups in the sciences.

Ecological studies underpin our understanding of ecosystem function and ecosystem services. Reflecting von
Humboldt's working methods, ecological research is now undertaken by teams of people working together, from many countries and cultures. Diverse groups tend to be more objective and attuned to solving problems than homogenous ones ${ }^{4}$. Mere representation is insufficient, though. People must be able to be themselves in their work. However, queer scientists feel they must downplay their sexual orientation or gender identity at work ${ }^{1}$, and they consistently report more negative experiences in the workplace than their straight co-workers ${ }^{5}$. This can lead to scientists leaving science, technology, engineering and mathematics (STEM) disciplines altogether ${ }^{6}$. Role models are an effective way of encouraging queer people to be authentic in science, and we should celebrate that Alexander von Humboldt found love with the men who accompanied him on his expeditions. Without that support, he may never have turned into an eminent ecologist and geographer. If we don't acknowledge the diversity of humanity, including scientists, science itself will be less inclusive, and less successful in tackling issues central to our world.

Further, truly being ourselves as scientists offers the opportunity to transform our scientific identity and our methods, and, through social action, inspire and give back to others ${ }^{7}$. Here, we take the opportunity to not only point to wider lesbian, gay, bisexual, transgender, queer and intersex (LGBTQI+) STEM platforms, such as 500 Queer Scientists (https:// www.500queerscientists.com/), LGBTQ+ STEM (https://lgbtstem.wordpress.com/) and Pride in STEM (https://prideinstem.org/) but also encourage reflection on the overlaps between environmentalism, colonialism and the practices of history that Humboldt's writing can also inspire . $^{8}$

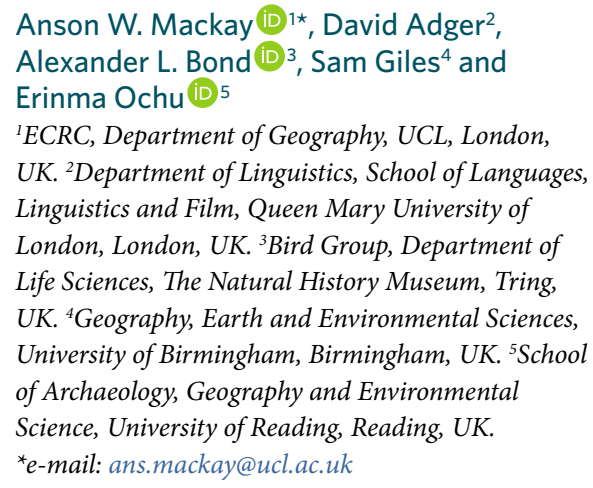

Published online: 4 November 2019

https://doi.org/10.1038/s41559-019-1025-9

\section{References}

1. Mattheis, A., De Arellano, D. C. R. \& Yoder, J. B. J. Homosex https://doi.org/10.1080/00918369.2019.1610632 (2019).

2. Wulf, A. The Invention of Nature: The Adventures of Alexander von Humboldt, the Lost Hero of Science (John Murray, 2015).

3. Nat. Ecol. Evol. 3, 1265-1266 (2019).

4. Apfelbaum, E. P., Phillips, K. W. \& Richeson, J. A. Perspect. Psychol. Sci. 9, 235-244 (2014).

5. Cech, E. A. \& Pham, M. V. Soc. Sci. 6, 12 (2017).

6. Exploring the Workplace for LGBT+ Physical Scientists (Institute of Physics, Royal Astronomical Society and Royal Society of Chemistry, 2019).

7. Ochu, E. in Doing Research in and on the Digital: Research Methods across Fields of Inquiry (eds Condie, J. \& Costa, C.) Ch. 11 (Routledge, 2018).

8. Sachs, A. Hist. Theor. 42, 111-135 (2003).

Competing interests

A.W.M., S.G. and E.O. are members of The Inclusion Group for Equity in Research in STEMM (https:// www.tigerinstemm.org/). The other authors declare no competing interests. 